\title{
ELCAPITALDE TRABAJO NETO Y EL VALOR EN LAS EMPRESAS \\ LA IMPORTANCIA DE LA RECOMPOSICIÓN \\ DEL CAPITAL DE TRABAJO NETO \\ EN LAS EMPRESAS QUE ATRAVIESAN \\ O HAN ATRAVESADO \\ CRÍSIS FINANCIERAS
}

María Marcela Rizzo. ${ }^{1}$

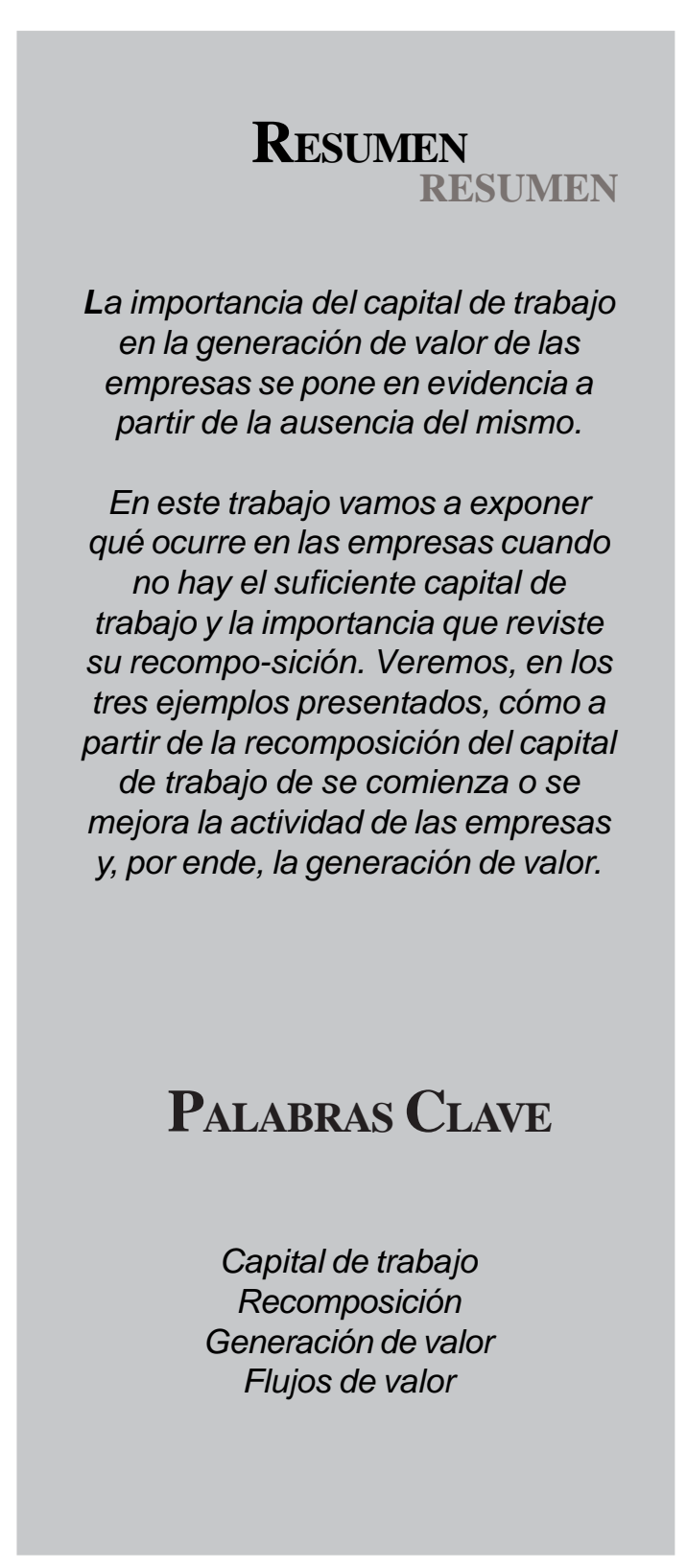

\section{RESUMEN \\ RESUMEN}

La importancia del capital de trabajo en la generación de valor de las empresas se pone en evidencia a

En este trabajo vamos a exponer qué ocurre en las empresas cuando no hay el suficiente capital de trabajo y la importancia que reviste su recompo-sición. Veremos, en los tres ejemplos presentados, cómo a artir de la recomposición del capital de trabajo de se comienza o se mejora la actividad de las empresas y, por ende, la generación de valor.

Este artículo fué entregado el 11 de octubre de 2007 y su publicación aprobada por el Comité Editorial el 29 de novimebre de 2007 
Figura 1

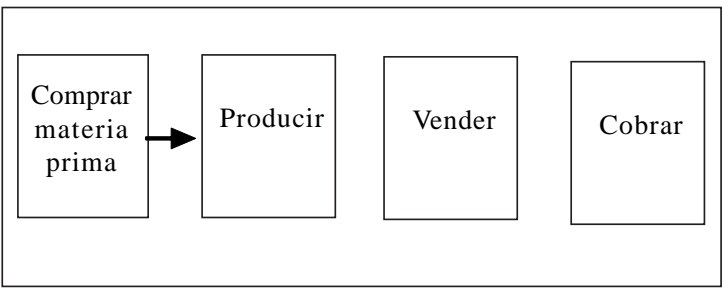

El tiempo que transcurre entre el momento en que se realiza la compra de materias primas y la cobranza de las ventas es lo que se conoce como el ciclo operativo del negocio. Dentro de este ciclo podemos diferenciar otro que está directamente relacionado con los ingresos y egresos de dinero, el cual recibe el nombre de ciclo de efectivo. Este comprende el periodo que transcurre desde que se realizan los pagos a proveedores hasta que se realizan las cobranzas de efectivo.

Gráficamente podemos ver los ciclos como se observa en la figura 2.

Analizando esta figura vemos que las necesidades de capital de trabajo surgen de las diferencias temporales existentes entre el ciclo operativo y el ciclo de efectivo de una empresa. De esta manera definimos capital de trabajo neto como la cantidad de trabajo necesaria para financiar el ciclo operativo de la empresa; de otra parte, la cantidad de dinero necesaria para financiar el ciclo efectivo se conoce como necesidades operativas de fondos. Así, calculamos el capital de trabajo neto como la diferencia entre el activo corriente y el pasivo corriente de la compañía. El capital de trabajo es el margen de seguridad para que la empresa opere sin tropiezos. La cantidad de dinero necesaria para financiar el ciclo de efectivo recibe el nombre de necesidades operativas de fondos.
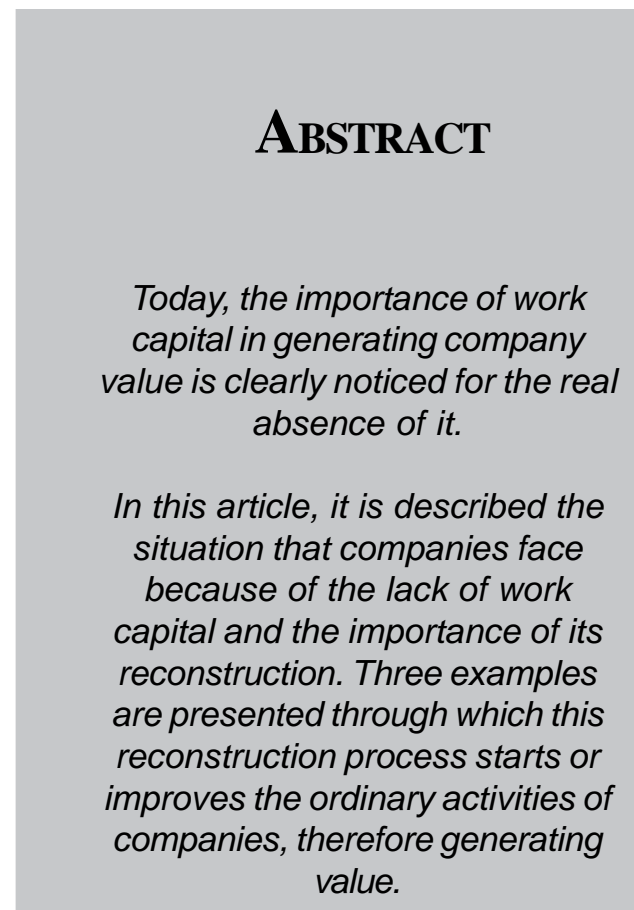

Abstract

Today, the importance of work capital in generating company value is clearly noticed for the real absence of it.

In this article, it is described the situation that companies face because of the lack of work capital and the importance of its reconstruction. Three examples are presented through which this reconstruction process starts or improves the ordinary activities of companies, therefore generating value.

\section{KEY WORDS}

\author{
Work capital \\ Reconstruction \\ Generation of value \\ Value flows
}


Figura 2

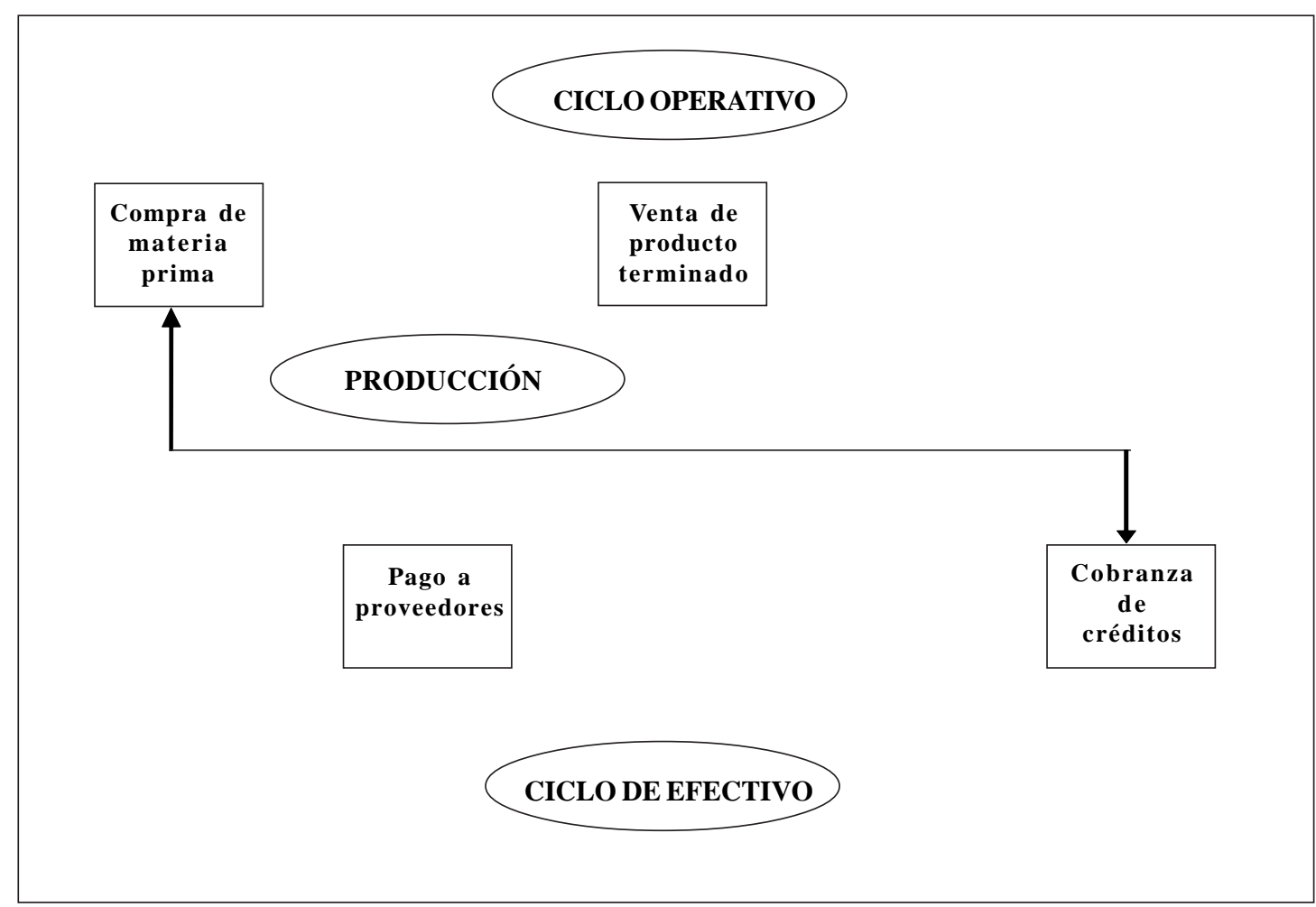

El cálculo de estas necesidades se realiza estableciendo la diferencia entre los activos corrientes y los pasivos espontáneos, siendo estos últimos los que surgen a partir del giro del negocio, tales como, las deudas con proveedores, los im-puestos y los sueldos que se devengan a fin de mes y se pagan a principios del mes siguiente.

Creemos importante destacar que el capital de trabajo de una empresa son las necesidades de efectivo de la misma para hacer frente a sus compromisos de corto plazo; es importante su gestión ya que la falta de cumplimiento de estos compromisos puede llevar a la empresa a un estado de insolvencia financiera ${ }^{1}$.

\subsection{Valor}

Desde el punto de vista financiero, el valor de una empresa es el valor actual de los flujos de caja, proveniente de los activos que esta generará. Todas las decisiones de los gerentes financieros deben estar orientadas a la maximización del valor de las empresas para sus accionistas.

1 Rizzo, M, Ameri, G. «Notas de clase Finanzas Corporativas « 


\section{2. ¿QUE OCURRE CUANDoNo haY CAPTTAL DE TRABAJO EN UNA EMPRESA?}

$\mathbf{T}$ trabajo es el margen de seguridad con el que cuentan las empresas para financiar su giro habitual, es fácil ver que cuando este escasea, ya que las empresas no pueden desarrollar ni sus actividades normales que son las que las ayudan a generar valor, ni buscar nuevos negocios para aumentar su valor. La falta de capital de trabajo, en la mayoría de los casos, es el comienzo de las dificultades financieras.

Las empresas, durante su operación, sufren problemas originados en la separación entre la propiedad y el control y en los contratos incompletos ${ }^{2}$.

Estos problemas se conocen con el nombre de conflictos de agencia y originan gastos que se conocen como costos de agencia.

Cuando las empresas atraviesan por dificultades financieras, los conflictos de agencia se acentúan. De la misma manera, se generan nuevos conflictos, que dificultan su operación, originados en la falta de dinero.

Las principales causas de las dificultades en la operación y en la generación de valor son:

- Las posibles violaciones de la regla de prioridad absoluta ${ }^{3}$ genera luchas internas entre propietarios, agentes y acreedores que intentan cobrar lo que más sea posible, antes de que la empresa se liquide o pase al proceso concursal. Estos desvíos de la regla de prioridad absoluta no sólo hacen que la operación de las empresas sea difícil, sino que también, la recuperación de las mismas sea más costosa ${ }^{4}$, ya que, cuando se producen, disminuye el valor de la opción futura de la empresa.

- Los accionistas y agentes tienden a aceptar proyectos de inversión con valor actual neto negativo ${ }^{5}$. Esto ocurre porque los accionistas son conscientes de que el riesgo que asumen al aceptar estos proyectos se puede ver recompensado con un alto beneficio; es decir, que aumenta el valor de la opción sobre el capital, ya que no tienen nada más que perder; lo máximo que pueden perder es lo que ya pagaron ${ }^{6,7}$.

- Los clientes frecuentemente cambian de proveedores por los posibles problemas a los que estarían expuestos a partir de las dificultades en las entregas que pueden tener las empresas que atraviesan por aprietos financieros. Asimismo, en algunos rubros la calidad del producto no es verificable y las empresas dependen mucho de su credibilidad para poder vender dicho

2 HART, Oliver «Firms. Contracts and Financial Structure» Clarendon Press Oxford 1995.

3 BETKER, Brian L «Management's Incentives, Equity Bargaining Power, and deviations from absolute priority in Chapter 11 Brankrupcies» The Journal of Business Vol. 68, pp. 161-183, April 1995.

4 FRANKS, Julian and TOROUS, Walter «An Empirical Investigation of U.S. Firms in Reorganization» The Journal of Finance Nro. 44, pp 747-769, July 1989.

5 GERTNER, Robert and SCHARFSTEIN, David «A Theory of Workouts and the Effects of Reorganization Law» Journal of Finance Nro. 46, pp 1189-1222, September 1991

6 MYERS, Stwart «Determinants of Corporate Borrowing» Sloan Working Papers, 1976

7 ASQUIT, Paul; GERTNER, Robert; SCHARFSTEIN, David «Anatomy of Financial Distress: An Examination of Junk Bonds Issuers» The Quarterly Journal of Economics, Vol 109, August 1994 
producto. Por lo tanto, en tales rubros el "financial distress" y la falta de credibilidad que esto trae aparejado, hace que los clientes desconfíen de la empresa en problemas y dejen de comprar. Típicamente éste es el caso de empresas donde el valor de los futuros negocios es tan grande que el cliente está seguro de que la empresa no mentirá por miedo a perderlos ${ }^{8}$. Lo mismo pasa con las que venden productos durables. Los clientes tienden a discriminarlas en el caso de que exista una alta probabilidad de quiebra y, por consiguiente, no estén disponibles el día de mañana para acceder a garantías o al "service" de los productos que venden.
- Estas empresas también tienen problemas con su personal, ya que cuando atraviesan por dificultades financieras, no sólo comienza a haber atrasos en el pago de sueldos, sino que también comienza a haber despidos, acentuándose esto último en las pequeñas empresas ${ }^{9}$ y en aquellas fuertemente endeudadas con bancos ${ }^{10}$.

- Los proveedores analizan cuidadosamente si les continúan vendiendo, ya que en caso de liquidación son acreedores quirografarios sin privilegio y, por lo tanto, tienen bajas probabilidades de cobrar el $100 \%$ de sus acreencias.

\section{RECOMPOSICIÓN DEL CAPITAL DE TRABAJO}

$\mathbf{E}_{\text {s }}$ reorganizar las empresas cuando estas llegan al "stress financiero".. Esto se puede hacer de distintas maneras, lo que depende de varios factores condicionantes, y no necesariamente financieros. Muchos de ellos están relacionados con factores administrativos, sociales, de contexto macroeconómico y también de índole personal de los directivos o responsables de la firma. Las medidas por tomar dependerán del tipo de solución que se quiera dar a las dificultades financieras por las que se atraviesa o en su defecto a las que se prevean.

En la reorganización financiera, la primera medida que debe tomarse es la reducción de gastos; reducción que debe ser realizada de forma inteligente. Es decir, no deben reducirse gastos y costos al azar. Es importante analizar primero qué incidencia tendrán las consecuencias de esas reducciones en el futuro desempeño de la empresa. Muchas veces, los empresarios toman decisiones sin tener en cuenta el verdadero impacto que estas tendrán. Por eso, es conveniente que antes de realizar despidos, cerrar plantas y hacer recortes se haga un estudio exhaustivo del desempeño de la empresa, de la posibilidad de prescindir de estos gastos y de la relación costo beneficio que producen esas erogaciones en el giro de la misma.

Una vez realizado el ajuste de estructura, debe considerarse la verdadera reorganización financiera, la cual consta de dos partes:

\footnotetext{
8 OPLER, Tim and TITMAN, Sheridan «Financial Distress and Corporate Performance» The Journal of Finance Vol 49, Jul 1994.

9 OGAWA, Kasuo «Financial Distress and Employment: The Japanese Case in the 90s» NBER Working Paper 9646, Abril 2003.

10 PADILLA, Jorge and REQUEJO, Alejandro «Financial Distress, Bank debt restructurings and layoffs» Spanish Economic Review, pp 73-103, 2000.
} 
- Reestructuración de activos.

- Reestructuración de pasivos o reestructuración financiera.

Cabe señalar que puede realizarse cualquiera de las reestructuraciones mencionadas indistintamente o una combinación de ambas.

\subsection{Reestructuración de activos}

La reestructuración de activos puede hacerse de varias maneras:

- Venta de activos. Hemos observado que lo primero que se hace en caso de reestructuración de activos es la venta de activos no corrientes, tales como, maquinarias, inmuebles, rodados, con el fin de conseguir dinero para continuar con la operación del negocio. Lo ideal sería que las empresas que reestructuran su activo trataran de deshacerse de los activos sobrantes o superfluos. Muchas veces se venden activos que son necesarios en el proceso productivo, con la idea de tercerizar estos procesos, lo que ocasiona que se obtengan fondos en el corto plazo, pero que, en el largo plazo, la falta de los mismos ocasione problemas.

- Reducción de gastos de capital y de investigación y desarrollo. Obviamente, empresas con dificultades para afrontar sus compromisos de corto plazo no realizan nuevas inversiones, salvo las estrictamente necesarias. Esto se debe básicamente a la falta de fondos $\mathrm{y}$ al aumento del costo de capital.
- Fusiones o adquisiciones. En este caso, la empresa que está atravesando por dificultades prefiere fusionarse o ser adquirida. En apariencia, estas soluciones son las mejores, pero analizando cuidadosamente el tema nos encontramos con dificultades importantes, tales como la determinación del precio de la compañía que se va a adquirir ${ }^{11}$, y problemas en la posterior operación, ocasionados por los choques culturales y la definición del "staff" de la nueva compañía ${ }^{12}$.

\subsection{Reestructuración de pasivos o reestructuración financiera}

La reestructuración financiera es uno de los puntos de inflexión más importantes en la vida de las empresas y en el estudio de las finanzas. Lo anterior, teniendo en cuenta que la reestructuración de pasivos o reestructuración financiera, es una toma de decisiones de largo plazo originada en problemas del corto plazo, a partir de la cual se define la continuidad de la firma y la nueva estructura de capital.

La estructura de capital es un factor importante en la determinación del valor de una empresa. Como se planteó anteriormente, , la definición de valor se apoya en dos factores importantes: los futuros flujos de fondos y la tasa a la que se descuentan esos flujos. El costo promedio de capital es la mínima rentabilidad exigida a las inversiones que realizan las empresas. Por esta razón es que es tan importante la reestructuración financiera, ya que de este proceso surgirá esta rentabilidad mínima, la cual es la definitoria de la aceptación de inversiones que generarán valor a las mismas.

\footnotetext{
${ }^{11}$ DAMODARAN, Aswath «Damodaran on Valuation», Wiley and Sons, USA, 1994

12 MASCAREÑAS, Juan «Fusiones y Adquisiciones de Empresas», 3 Edición, Mc Graw Hill , Madrid
} 
La incapacidad del pago de deuda es un problema que, en la mayoría de los casos, surge de la mala administración del capital de trabajo. Teóricamente, la insolvencia financiera es la desencadenante de los concursos de acreedores, aunque, a veces, la iliquidez es la causante de la falta de pago de obligaciones

que desencadenan pedidos de quiebra que, luego, de acuerdo con la Ley de Concursos y Quiebras, se pueden transformar en concurso de acreedores.

La reestructuración del pasivo de una empresa, desde el punto de vista financiero, se puede hacer de las siguientes formas:

- Refinanciación de deudas: consiste básicamente en transformar deudas de corto plazo en deudas de largo plazo; esto se puede hacer así:

- Negociaciones con bancos y otros acreedores: en este caso lo que hace la empresa es repactar sus pagos, transformándolos de obligaciones de corto plazo en obligaciones de largo plazo. Generalmente, las deudas que se repactan son las deudas con bancos y con proveedores.

- Emisión de nuevos valores de deuda: se emiten títulos de deuda (bonos). Esto conlleva el objetivo de poder cancelar los compromisos de corto plazo con papeles de largo plazo. Por lo general, estas nuevas emisiones de bonos reciben el nombre de "bonos basura" que son bonos de alto riesgo, baja calificación y, por lo tanto, alta rentabilidad.
- Capitalización de deudas: consiste en cambiar deuda por capital a los acreedores. Los acreedores pueden ser empleados 0 proveedores.

Dentro de las negociaciones que se hacen en el marco del Concurso Preventivo, hay dos propuestas que tradicionalmente son las fundamentales. Estas son la quita y la espera, que el deudor propone a sus acreedores quirografarios en su propuesta concursal.

La reforma en Ley de Concursos y Quiebras introduce las siguientes maneras de reestructurar las empresas que atraviesan dificultades financieras, con el fin de preservar las fuentes de trabajo ${ }^{13}$.

- Constitución de una sociedad con los acreedores quirografarios en la que estos tengan calidad de socios.

- Reorganización de la sociedad deudora.

- Administración de todos o parte de los bienes en interés de los acreedores. Con esta propuesta lo que hace el deudor es comprometerse a administrar parte de los bienes de la empresa para pagar sus deudas pre concursales.

- Emisión de bonos convertibles en acciones.

- Constitución de garantías sobre bienes de terceros, las cuales pueden ser, por ejemplo, sobre bienes de los propietarios.

- Cesión de acciones de otras sociedades.

- Capitalización de créditos, inclusive de acreedores laborales, en acciones o en un programa de propiedad participada o en cualquier otro acuerdo que obtenga las mayorías requeridas.

\footnotetext{
${ }^{13}$ Ley de Concursos y Quiebras.
} 
La reestructuración financiera de empresas puede hacerse en forma pública o privada; es decir, dentro del marco de la Ley de Quiebras y a través del Poder Judicial o haciendo una convocatoria privada de los acreedores. La nueva Ley de Quiebras también introdujo la figura del Acuerdo Preventivo Extrajudicial que permite a las empresas reestructurar su deuda en forma semi privada, homologando judicialmente el acuerdo con sus acreedores, una vez realizado este.

Todas las acciones llevadas a cabo en la reorganización financiera, tienden a que las empresas puedan recuperar su capital de trabajo, ya que sin él no pueden operar.

\section{LOS FLUJOS QUE GENERAN EL VALOR DE LAS EMPRESAS ${ }^{14}$}

\section{$\mathbf{E}$} cuando se analiza la compra de una empresa o se toman decisiones con respecto a la continuidad de la misma, deben analizarse los flujos provenientes de sus activos..

Estos flujos pueden separarse en dos componentes que son:

- Flujos provenientes del giro habitual del negocio.

- Flujos provenientes de actividades no habituales.

A su vez, los flujos provenientes del giro habitual del negocio los podemos dividir en:
- Flujo de efectivo operativo: es el generado por la actividad habitual del negocio. Este flujo es el que va a indicar la recuperación de la empresa, ya que se genera a partir del Estado de Resultados; es decir, de lo producido por las ventas habituales del negocio.

- Flujo proveniente de la variación del capital de trabajo neto: es el proveniente de la inversión o desinversión producida por las necesidades del giro habitual del negocio.

Los flujos provenientes de actividades no habituales son los flujos provenientes de la variación de activos no corrientes; es decir, los originados en las compras y ventas de activos no corrientes.

Escribiendo esto en fórmulas tenemos que:

\section{Flujo ProvenienteFlujo de Efectivo de los Activos \\ (FEO)}

$\begin{array}{ccc}\text { Flujo Proveniente } & \text { Flujo Proveniente } \\ \text { de la variación } & + & \text { de la variación } \\ \text { de Capital de Trabajo Neto } & \text { de Activos Fijos }\end{array}$

14 Ross, S y Otros, Finanzas Corporativas, 5 Ed. McGraw Hill, México, 2000. 
Analizaremos brevemente cómo se componen estos flujos ${ }^{15}$ :

- Flujo de Efectivo Operativo: este flujo surge del Estado de Resultados. Recor-dando la forma básica del Estado de Resultados, tenemos que el Resultado Neto se calcula de la siguiente manera:

\section{GENERACION \\ DE FLUJOS \\ DE FONDOS}

\section{PERTENENCIA \\ DE LOS FLUJOS \\ DE FONDOS}

\begin{tabular}{|c|c|c|c|}
\hline \multicolumn{2}{|c|}{ Ventas } & $\mathrm{Si}$ & F.E.O \\
\hline Menos: & Costos & $\mathrm{Si}$ & F.E.O \\
\hline \multicolumn{2}{|c|}{ Resultado bruto } & & \\
\hline Menos: & Depreciaciones & No & \\
\hline \multicolumn{3}{|c|}{$\begin{array}{l}\text { Resultado antes } \\
\text { de intereses e impuestos }\end{array}$} & \\
\hline Menos: & Intereses pagados & Si & $\begin{array}{l}\text { Flujo destinado } \\
\text { a Acreedores }\end{array}$ \\
\hline \multicolumn{2}{|c|}{ Resultado imponible } & & \\
\hline Menos: & Impuestos & $\mathrm{Si}$ & F.E.O \\
\hline
\end{tabular}

De las partidas expresadas en el estado de resultado vemos que las depreciaciones no generan movimientos de fondos y que los intereses no corresponden al flujo de efectivo operativo, ya que son la retribución a quienes le prestan dinero a la empresa. Teniendo en cuenta lo anterior, el Flujo de Efectivo Operativo se puede calcular de dos formas:

- Partiendo del Resultado Bruto y, de acuerdo con el análisis hecho en la Figura 1, al mismo le restamos los impuestos, ya que los intereses pertenecen a los acreedores y las depreciaciones no generan flujos de caja; obtenemos así el Flujo de Efectivo Operativo ( F.E.O).

Mentas
$\frac{\text { Renos: } \quad \text { Costos }}{\text { Resultado Bruto }}$
$\frac{\text { Menos: } \quad \text { Depreciaciones }}{\text { Resultado antes }}$
de intereses e impuestos
Menos: $\quad$ Intereses
Resultado Imponible
Menos: Impuestos

Resultado neto
F.E.0. $=$ Resultado bruto + impuestos (con signo negativo si se pagan, y con signo positivo si no se pagan

${ }^{15}$ Rizzo, M y Ameri.G., Notas de Cátedra Finanzas Corporativas. 
- Partiendo del resultado neto y, de acuerdo con el análisis hecho en la Figura 1, le sumamos al mismo los intereses y las depreciaciones y obtenemos el Flujo de Efectivo Operativo.

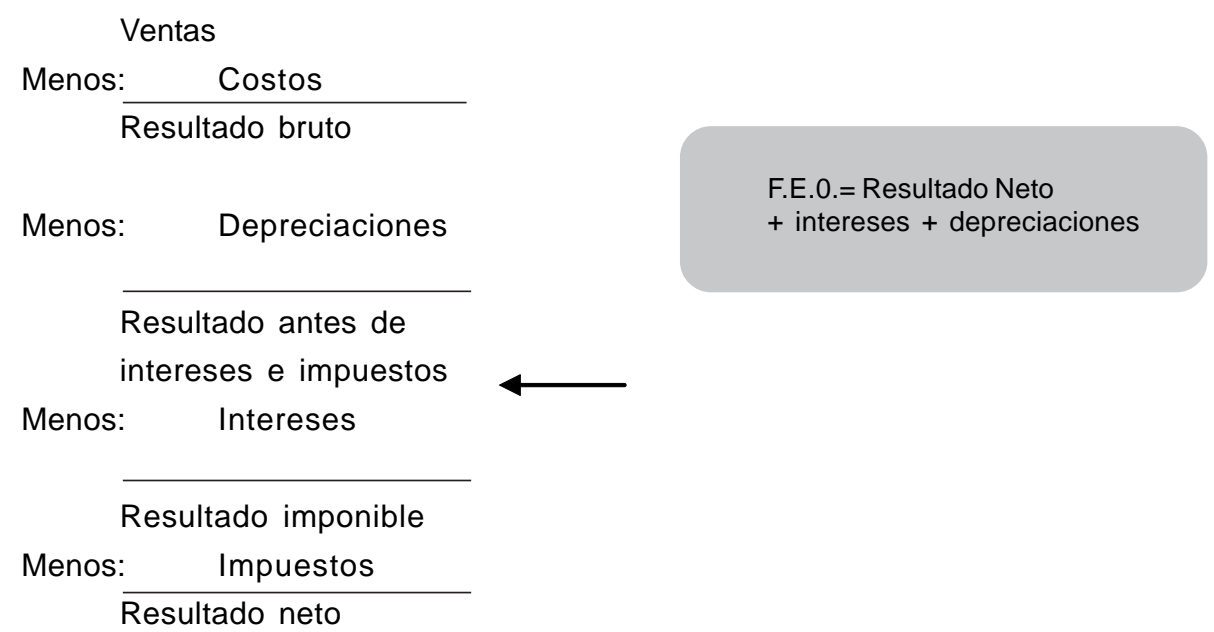

Así vemos que el Flujo de Efectivo Operativo puede calcularse de dos maneras; ambas surgen de eliminar del estado de resultados las partidas que no generan flujos de caja y las que no son parte del giro habitual del negocio.

- Flujo de efectivo proveniente de la variación del capital de trabajo neto: como sabemos, las variaciones surgen de la comparación entre el estado final y el estado inicial. Así, la variación del capital de trabajo neto, se calcula como:

Capital de trabajo neto = capital de trabajo neto final - capital de trabajo neto inicial

Cabe recordar que el capital de trabajo neto se calcula como la diferencia entre el activo corriente y el pasivo corriente.

Es importante analizar el signo de esta variación y el signo del flujo que esta variación produce:

- Si la variación del capital de trabajo neto es positiva, implica que el capital de trabajo neto de la compañía aumentó, lo que significa que la empresa invirtió en él; es decir, que se generó un flujo de efectivo negativo para la compañía, ya que hubo una salida de efectivo. Ejemplos:
- Si se aumenta el plazo de crédito a los clientes de la compañía, el activo corriente de la misma aumenta ya que aumentan los créditos por ventas; esto significa una variación positiva del capital de trabajo neto de la compañía. Sin embargo, en términos de flujos de caja, la variación es negativa ya que los mismos disminuyen, porque al aumentar el plazo de crédito disminuyen los ingresos y los egresos siguen siendo iguales.

- Si se aumenta el inventario de mercaderías, el activo corriente de la compañía aumenta, incrementando el capital de 
trabajo neto de la misma; esto significa una variación positiva del mismo. En términos de flujos de caja, la variación es negativa, ya que los inventarios no generan ingresos estando en los depósitos de la empresa, pero deben pagarse. Entonces el flujo de fondos es negativo.

- Si la variación del capital de trabajo neto es negativa, significa que la compañía desinvirtió en él; es decir, que se generó un flujo de efectivo positivo para la empresa, ya que hubo un ingreso de efectivo.

Ejemplos:

- Si se disminuye el plazo de crédito a los clientes de la compañía, el activo corriente de la misma disminuye ya que disminuyen los créditos por ventas; esto significa una variación negativa del capital de trabajo neto de la compañía. Sin embargo en términos de flujos de caja, la variación es positiva ya que los mismos aumentan, porque al disminuir el plazo de crédito, aumentan los ingresos y los egresos siguen siendo iguales.

- Si se disminuye el inventario de mercaderías, el activo corriente de la compañía se reduce, disminuyendo el capital de trabajo neto de la misma; es decir, hay una variación negativa del mismo, pero en términos de flujos de caja la variación es positiva, ya que la venta de los inventarios genera ingresos, que son flujos de efectivo positivos.

Resumiendo, tenemos que:

\begin{tabular}{|c|c|c|}
\hline $\begin{array}{l}\text { SIGNODELA } \\
\text { VARIACIÓN }\end{array}$ & SIGNIFICADO & $\begin{array}{c}\text { FLUJO DE CAJA } \\
\text { PRODUCIDO }\end{array}$ \\
\hline Positivo & $\begin{array}{r}\text { Inversión } \\
\text { en Capital } \\
\text { de Trabajo } \\
\text { Neto }\end{array}$ & Negativo \\
\hline Negativo & $\begin{array}{l}\text { Desviación } \\
\text { en Capital } \\
\text { de Trabajo } \\
\text { Neto }\end{array}$ & Positivo \\
\hline
\end{tabular}

- Flujos provenientes de la variación de activos no corrientes. Recordando que los activos no corrientes son aquellos que no son adquiridos con la intención de venderse en un periodo menor a un ejercicio económico, podemos decir que estos son, por ejemplo, los inmuebles, las maquinarias, rodados, marcas y patentes.

La variación de los activos no corrientes se calcula de la siguiente manera:

Activos No corrientes $=$ Activos no corrientes finales - activos no corrientes iniciales 
Es importante señalar que en los estados contables, los activos no corrientes se expresan netos de las amortizaciones; es decir, que en este caso, a los activos no corrientes finales hay que sumarles las depreciaciones. La fórmula de la variación de activos no corrientes es:

Activos No corrientes $=$ Activos no corrientes finales + depreciaciones - activos no corrientes iniciales

Asimismo, debemos tener en cuenta que la variación de activos no corrientes es la diferencia entre las compras y las ventas de los mismos durante el ejercicio económico en estudio.

Con respecto al signo de la variación y al signo del flujo de caja que esta produce, debemos hacer las siguientes consideraciones:

- Si la variación tiene signo positivo, significa que las compras de activos no corrientes fueron mayores a las ventas de los mismos; es decir, que los activos no corrientes de la compañía aumentaron. Este aumento, producido por una compra, provoca un egreso de efectivo; o sea, el flujo de caja, proveniente de la variación de activos no corrientes, en este caso, será negativo.

- Si la variación tiene signo negativo, significa que las ventas de activos no corrientes fueron mayores que las compras de los mismos; es decir, que los activos no corrientes de la compañía disminuyeron. Esta disminución produjo un ingreso de dinero; por lo tanto, el flujo de efectivo proveniente de la variación de activos no corrientes en este caso será positivo.

Resumiendo tenemos que:

\begin{tabular}{|c|c|c|}
\hline $\begin{array}{c}\text { SIGNODELA } \\
\text { VARIACIÓN }\end{array}$ & SIGNIFICADO & $\begin{array}{c}\text { FLUJO DE CAJA } \\
\text { PRODUCIDO }\end{array}$ \\
\hline Positivo & $\begin{array}{c}\text { Las compras } \\
\text { fueron mayores } \\
\text { que las ventas }\end{array}$ & Negativo \\
\hline Negativo & $\begin{array}{r}\text { Las ventas } \\
\text { fueron mayores } \\
\text { que las } \\
\text { compras }\end{array}$ & Positivo \\
\hline
\end{tabular}

A continuación analizaremos el comportamiento de estos flujos cuando las empresas operan normalmente y cuando atraviesan por dificultades financieras. 
En caso de que la empresa opere normalmente, el flujo de efectivo operativo, que es el que proviene de las ventas, es creciente año a año; mientras que el flujo proveniente de la variación de capital de trabajo neto debe ser negativo, ya que dentro de este flujo se encuentran los créditos por ventas que deberían tener una tendencia creciente si aumenta el volumen de ventas, por lo menos en los años de crecimiento de la empresa. Los flujos provenientes de la variación de activos no corrientes en empresas que están en normal operación deben tender a ser negativos, ya que indican la inversión en activos no corrientes. De esta manera vemos que la generación de valor de las empresas se indica por la decisión de reinvertir lo producido en créditos por ventas o en activos no corrientes.

En caso de que la empresa comience a transitar por el camino de las dificultades financieras veremos que los flujos provenientes de la variación de capital de trabajo neto seguirán siendo positivos, pero a costa del incremento de las cuentas por pagar; es decir, a costa del mayor endeudamiento en el corto plazo con los proveedores. Es probable también que los flujos provenientes de la variación de activos no corrientes sean positivos ya que la empresa comenzará a vender algunos activos para conseguir efectivo.

Cuando la empresa se encuentra en una situación visible de dificultades financieras, el flujo de efectivo operativo tiende a disminuir, pues esta pierde la confianza de sus clientes y proveedores; también tiende a ser cero o negativo el flujo proveniente de la variación de capital de trabajo, mientras que los activos no corrientes no pueden variar.

El proceso de reestructuración financiera, descrito anteriormente, tiene como consecuencia fundamental la transformación de deudas exigibles en el corto plazo en deudas de largo plazo; de esta manera se logra la recomposición del capital de trabajo neto..

La recomposición del capital de trabajo neto de las empresas es un signo evidente de su recuperación financiera, ya que, a partir de la generación del mismo. se puede generar valor para la empresa. Con la recomposición del capital de trabajo comienza nuevamente la generación de flujos de fondos y, por lo tanto, la generación de valor.

\section{CASOS DE ANÁLISIS}

\section{V} amos a contrastar tres casos de empresas que han reestructurado su deuda. El primero de estos es Aerolíneas Argentinas, una empresa que nació como una empresa de capitales estatales y se privatizó en los noventa. El origen de su concurso de acreedores fue la imposibilidad de operar, es decir, la falta de capital de trabajo. El segundo, corresponde a la empresa Multicanal, empresa parte de un grupo económico. La causa de la reestructuración de su deuda fue la imposibilidad de hacer frente a los compromisos que tenía contraídos en el exterior. En este caso disponía de capital de trabajo y podía hacer frente a sus compromisos habituales. El origen de este problema fue la devaluación argentina. El tercero de los casos es uno que políticamente es cuestionable, pero que analizaremos solamente desde la óptica financiera; el caso de una cooperativa de ex empleados que reestructuró una empresa. 


\subsection{Caso aerolineas argentinas}

Aerolíneas Argentinas fue creada durante la primera presidencia de Juan Domingo Perón, el 7 de diciembre de 1950, bajo los decretos 20.099 y 26.100 y en la Jurisdicción del Ministerio de Transporte. Su función era: "entender todo lo referente a la explotación y realización del servicio público de transportes aéreos comerciales, de cabotaje e internacionales, en un todo de acuerdo y con sujeción a la política que en esa materia fije el Poder Ejecutivo". De esta manera, nace Aerolíneas Argentinas como línea aérea bandera. La empresa operaba, en ese momento, 46 escalas nacionales, 4 regionales y 12 internacionales.

En su primer año de vida, arrojó un déficit de 42 millones de pesos; cinco años más tarde el déficit acumulado era de 350 millones de pesos. Esta situación se revirtió veinticuatro años después de su creación.

Desde los orígenes de la compañía hubo intentos de privatizarla. El último intento, antes de su privatización, fue en el año 1983, durante el gobierno de Raúl Alfonsín. Este intento no tuvo éxito ya que no tuvo apoyo ni de los gremios, ni del bloque justicialista, que era mayoría en el Parlamento.

El siguiente intento fue el que finalmente tuvo éxito, durante el gobierno de Carlos Menem. El gobierno tomó la privatización de Aerolíneas Argentinas como caso testigo de las privatizaciones. El sistema que utilizaron para la privatización fue el de Licitación Pública. Los oferentes debían organizarse en grupos integrados por líneas aéreas extranjeras, bancos tenedores de deuda externa y capitales nacionales. Así, luego de un proceso bastante largo y tortuoso de selección, Aerolíneas Argentinas fue comprada por un consorcio formado por Iberia, Swiss Bank y Austral.
Austral interviene en el consorcio con el fin de evitar tener competencia en el mercado nacional.

Dentro del acuerdo de compra, se permitió a los compradores cargar los costos de la adquisición de la empresa en los activos de la misma, generando una deuda muy gravosa con acreedores bancarios.

La preadjudicación de la compra de Aerolíneas Argentinas por parte del consorcio Iberia, Swiss Bank y Austral se produce el 17 de noviembre de 1990. La oferta era la siguiente: un pago efectivo de U\$D 260 millones, más U\$D 1.610 millones en títulos de deuda externa. En una primera cuota se abonarían U\$D 130 millones al contado, mientras que los U\$D 130 millones restantes se pagarían en 10 cuotas, la primera de las cuales vencía a los cinco años de la entrega de la compañía. En cuanto al Plan de Inversiones se comprometía a un monto de U\$D 683 millones en cinco años. Se planteaba incorporar quince aeronaves para conformar una aeroflota de treinta y cuatro aviones, que realizarían ciento treinta y nueve viajes semanales a América, veintitrés a Europa y uno a Oceanía. Se calculaba, además, que Aerolíneas aportaría en impuestos la suma de U\$D 23 millones al año y no demandaría subsidios del Estado.

En febrero de 1994 se establece Interinvest S.A., una sociedad inversora y financiera creada para poder realizar las operaciones de traspaso de acciones. En diciembre de ese mismo año, el gobierno español lanza una serie de medidas destinadas a salvar a Iberia, afectada por el contexto de recesión económica ocasionado por la Guerra del Golfo y por el descenso de las tarifas aéreas. En ese mismo año, había crisis del sistema monetario europeo y dificultades en el proceso de privatización de las filiales sudamericanas, especialmente Aerolíneas Argentinas. Las 
medidas que planteaba el gobierno español eran las siguientes:

- Inyectar capital a Iberia a través de Teneo (Sociedad Estatal de Participaciones Industriales).

- Desprenderse del $13 \%$ de Ladeco, del $100 \%$ del Grupo Interinvest y del 10\% del paquete accionario de Aerolíneas Argentinas.

Para el futuro de Aerolíneas la clave estaba dada por la constitución de Andes Holding BV. Esta era una sociedad anónima de derecho holandés, constituida con el único objetivo de adquirir las participaciones de Iberia para revenderlas posteriormente. Su capital ascendía a U\$D 10 millones y estaba formado en un $42 \%$ por Teneo (SEPI, Sociedad Estatal de Participaciones Industriales) y en un 58\% por Merryl Lynch y Bankers Trust. Las operaciones por realizar eran las siguientes:

- Se transferirían los créditos de Iberia sobre Arsa (Aerolíneas Argentinas S.A.).

- Se haría un nuevo aporte de capital (préstamo Iberia o mercados financieros), con el cual Interinvest compraría la deuda de ARSA con terceros $y$, posteriormente, efectuaría un aporte irrevocable en beneficio de ARSA, absorbiendo las deudas de la misma.

- Se transferiría a Interinvest una parte de las acciones de Arsa propiedad directa de Iberia y correspondientes al $10 \%$ del capital de Arsa.

El resultado de todas estas operaciones sería una sociedad con el capital saneado. En 1998, Iberia deja de ser propietario de ARSA porque transfiere su participación accionaria a Andes Holding y éste se la transfiere a Interinvest.
En 1997 trascendió que American Airlines había comprado el $8,5 \%$ de Arsa y que el compromiso de la nueva propietaria e Iberia era conseguir nuevos inversores para Arsa. Recién, en octubre de 1998, American Airlines comenzó a operar Arsa, pero a principios de 2000 cedió su participación. Cuando American Airlines se retira, la Sepi retoma el control y propone, en junio de 2000, el Plan Director que, según ellos, iba a permitir el saneamiento de la compañía. El plan de la SEPI contenía un sinnúmero de exigencias para los gobiernos español y argentino, hablaba de reducciones de sueldos y también contenía exigencias para Aeropuertos 2000. Este plan trajo muchas dudas entre el personal de ARSA y, a

partir del mismo, comenzaron las marchas y bloqueos de salidas de aviones, no sólo de Arsa sino también de Iberia. Los gremios habían salido a buscar alternativas al Plan presentado por la Sepi y contrataron a Randolph Babbit, que había diseñado la salida financiera de United Airlines en los 90, para que presentara otro plan, que se llamó "Plan Restaurar". Esta presentación tampoco tuvo éxito. Las luchas económicas y políticas duraron hasta junio de 2001 y así el 21 de Junio de 2001 salió en todos lo diarios del país la noticia de que Aerolíneas Argentinas SA había presentado su concurso de acreedores.

Luego de presentar el concurso preventivo, la Sepi siguió intentando vender la empresa. Finalmente, en octubre de 2001 se adjudica la empresa al Grupo Air Comet - Marsans. Este grupo español, al valuar la compañía, no sólo había realizado la valuación con los métodos tradicionales, sino que había tenido en cuenta el potencial de las rutas que poseía Arsa en ese momento.

El hecho de que la empresa fuera vendida y su gerencia cambiara de manos no le quitó fuerza a la cohesión sindical que existe entre los gremios aeronáuticos. 
El 27 de diciembre de 2002, los diarios daban la noticia de que Aerolíneas había salido de su concurso preventivo y que iba a pagar el $40 \%$ de la deuda en tres cuotas ( $10 \%$ a los 90 días, $35 \%$ a los 360 días y 55\% a los 720 días).

El concurso preventivo es la recomposición del capital de trabajo neto. En este caso, la empresa no sólo transformó pasivo corriente en pasivo no corriente (a partir de los plazos obtenidos), sino que también disminuyó su deuda en un $60 \%$ con la quita obtenida.
A partir de este momento, la compañía comenzó a anunciar incremento en sus ventas, en sus utilidades y, también, la compra de nuevas rutas. La evolución del número de pasajeros transportados y la cantidad de horas voladas presentadas en las figuras 3 y 4 muestra claramente cómo la recomposición del capital de trabajo neto de la empresa generó una mejor operatividad, con la consecuente generación de valor.

Figura 3. Pasajeros transportados

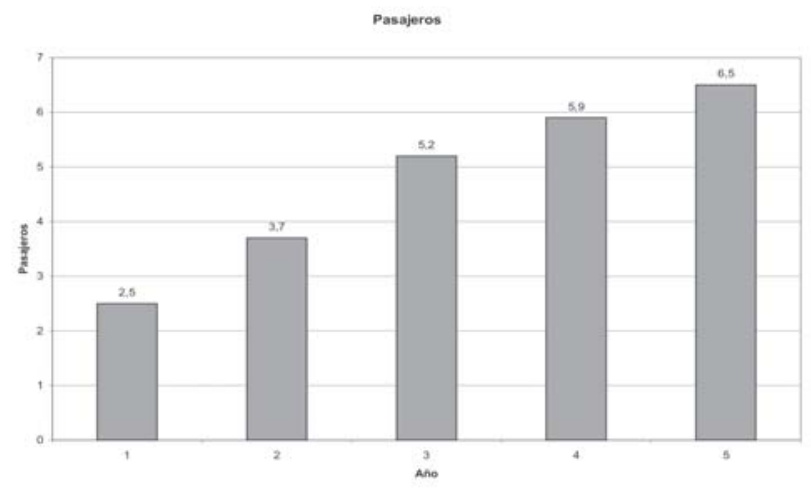

ruente: La Nacıon 14 de Junı 2006

Figura 4. Horas Voladas

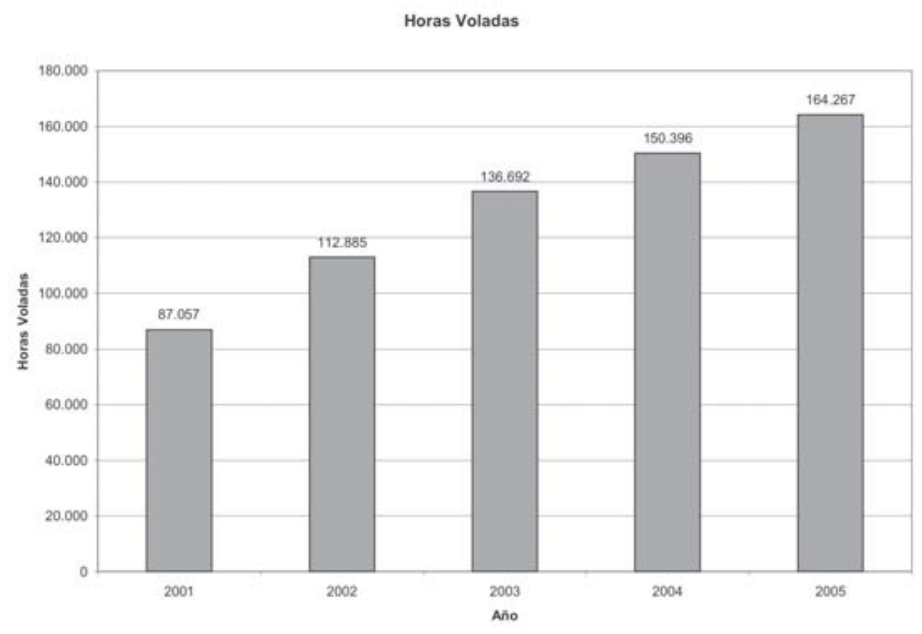

Fuente: La Nación 14 de Junio 2006 


\subsection{Caso multicanal}

Multicanal fue constituida en 1991 e incorporada al Grupo Clarín en octubre de 1992. Nació como un Sistema de Televisión por Cable. En poco tiempo se posicionó como líder en Latinoamérica, mediante una política de adquisiciones que le permitieron aumentar su participación en el mercado. Ha protagonizado en la Argentina un proceso de expansión y enriquecimiento de la oferta de contenidos de televisión paga, con la incorporación de señales internacionales como Cinecanal, Cinemax, Fox, Nickelodeon, Cartoon Network y Galicia $T V$, junto a una excelente oferta de señales locales como TN, TyC Sports y Volver. En agosto de 1997 inauguró en la Argentina el sistema de Programación Premium, basado en la oferta de fútbol en vivo y programación erótica. Mediante una cuota adicional al abono básico, los clientes reciben programación de su especial interés, seleccionada a partir de una oferta de contenidos exclusivos, que varía de acuerdo a cada región. Su desarrollo en el negocio continuó ya que también es proveedor de servicios de Internet. A fines de 2002, Multicanal era uno de los mayores operadores de cable del país pues al 31 de diciembre de 2002 tenía aproximadamente 950.000 abonados, de los cuales el 87\% correspondía al país y el resto a Uruguay y Paraguay. A fines del 2002, debido a la profunda recesión que había en el país, todo el sector de las empresas de cable sufrió una baja importante en el número de clientes. A partir de esta situación tuvieron que tratar de mejorar la rentabilidad de las empresas.

En el cuadro número 1 vemos la cronología del endeudamiento de Multicanal:

Cuadro 1

\begin{tabular}{|l|c|c|c|}
\hline Fecha & Serie & Monto & Vencimiento \\
\hline Enero 1997 & Serie A & U\$S 125.000.000 & $01 / 02 / 2002$ \\
\hline Enero 1997 & Serie B & U\$S 125.000.000 & $01 / 02 / 2007$ \\
\hline Marzo 1998 & Serie C & U\$S 150.000.000 & $15 / 04 / 2018$ \\
\hline Marzo 1999 & Serie E & U\$S 175.000.000 & $15 / 04 / 2009$ \\
\hline Febrero 2000 & Serie G & U\$S 150.000.000 & $18 / 07 / 2002$ \\
\hline Enero 2001 & Serie I & U\$S 14.000.000 & $21 / 08 / 2001$ \\
\hline Agosto 2001 & Serie J & U\$S 144.000.000 & $22 / 08 / 2003$ \\
\hline
\end{tabular}

El 1 de febrero de 2002, la sociedad se vio en la obligación de postergar los pagos y los vencimientos correspondientes a capital e intereses que vencían en 2002 y los intereses de las ON que vencían en 2007. Posteriormente, tuvo que postergar los vencimientos de las otras obligaciones emitidas por la empresa. 
Durante el mes de febrero del año 2003 se presentaron 21 pedidos de quiebra contra la empresa. En los primeros meses de este año, la empresa había iniciado su proceso de reestructuración. La misma iba a ser ejecutada a través de un Acuerdo Preventivo Extrajudicial o APE, que es un mecanismo similar al "Prepackaged Chapter" 11 de la Ley de Quiebras de los Estados Unidos. En las notas de los Estados Contables cerrados el 31/12/ 2003, se informa que acreedores del exterior habían iniciado un proceso contra la empresa en los tribunales de New York, a los que esta se opone presentando un recurso. La Justicia determina que la presentación por parte de los acreedores de la empresa no les impide participar del APE, si así lo quisieran. La propuesta del APE consistía básicamente en cambiar títulos a diez y a siete años. El monto de deuda reestructurada ascendía a 337 millones de dólares. Finalmente, el 14 de abril de 2004 se homologó el APE pedido por la empresa.

Desde el punto de vista de la operación, fue necesario el concurso preventivo de la misma, pero por razones de endeudamiento de largo plazo. Por lo tanto, no hubo recomposición de capital de trabajo, ya que la empresa era operable.

\subsection{Caso cooperativa harinera saladillo}

El molino harinero SICSA SA funcionaba en Saladillo, provincia de Buenos Aires. En el año 1995 comenzaron sus problemas financieros y, así, el 20 de octubre de 1995 dieron licencia a todos los obreros por primera vez. Luego de varios incidentes similares, en 1997 se decretó su quiebra y dejó de operar. A fines del año
2002, el molino estaba en instancias de remate. Un grupo de ex trabajadores había formado una cooperativa de trabajo con el fin de pedir continuar con su explotación. Estos estaban agrupados bajo el padrinazgo de la FECOOTRA.

A fines del año 2002, el Molino estaba camino a la liquidación; es decir, su activo no sólo no alcanzaba para cubrir sus pasivos, sino que la empresa era financieramente inoperable. Los ex empleados habían logrado que el Juez interveniente en la causa les diera la "tenencia precaria", con el fin de que reanudaran la explotación del mismo. El 8 de agosto de 2002 se inauguró la "Cooperativa de Trabajo Molinera Saladillo Limitada". El 19 de marzo de 2003 se realizó la primera molienda. Se realizaban trabajos "a facon" y se quedaban con algún subproducto. Un mes después de la primera molienda ya trabajaban en dos turnos.

Actualmente, el molino sigue funcionando, pero con problemas internos originados por la falta de profesionalidad de la gerencia.

En este caso, la empresa era totalmente inoperable, ya que en quiebra no tenía capital de trabajo neto; esto muestra claramente cómo la generación de capital de trabajo neto hace que la empresa sea operable y genera valor. La regeneración del capital de trabajo se produjo a partir de tres fuentes:

- El trabajo de los propios empleados. Los miembros de la cooperativa trabajaron retirando muy poco dinero.

- La cooperativa comenzó trabajando "a façon".

- Crédito que les proporcionaron los proveedores. 


\section{ConClusiones}

En el trabajo hemos planteado la relación existente entre la generación de valor en las empresas y la existencia de capital de trabajo. La medida financiera de valor de una empresa es la capacidad de generar flujos de fondos de los activos de la misma. Esto está íntimamente relacionado con el capital de trabajo de las empresas ya que este les da la capacidad para operar.

Las empresas que atraviesan por dificultades pierden su capacidad de generar valor y de ser operadas, ya que no tienen capital de trabajo neto.

Con el fin de demostrar nuestra postura hemos presentado tres casos de empresas que han reestructurado su deuda por diversas razones.
En el caso Aerolíneas, vemos cómo la recomposición del capital de trabajo generó un incremento en la capacidad generadora de valor de la empresa, ya que le produjo la posibilidad de tener nuevas rutas y transportar más pasajeros, entre otras. Mientras que en el caso Multicanal, la empresa era operativa al plantear la refinanciación de sus pasivos; por lo tanto, esta situación no produjo cambios en la generación de valor. En el último caso, un caso extremo, pues la empresa no era operativa, vemos cómo la operación de la misma y la regeneración del capital de trabajo se dio a partir de tres fuentes: el trabajo de los propios empleados, retirando muy poco dinero; trabajando "a façon".y crédito proporcionado por los proveedores. 

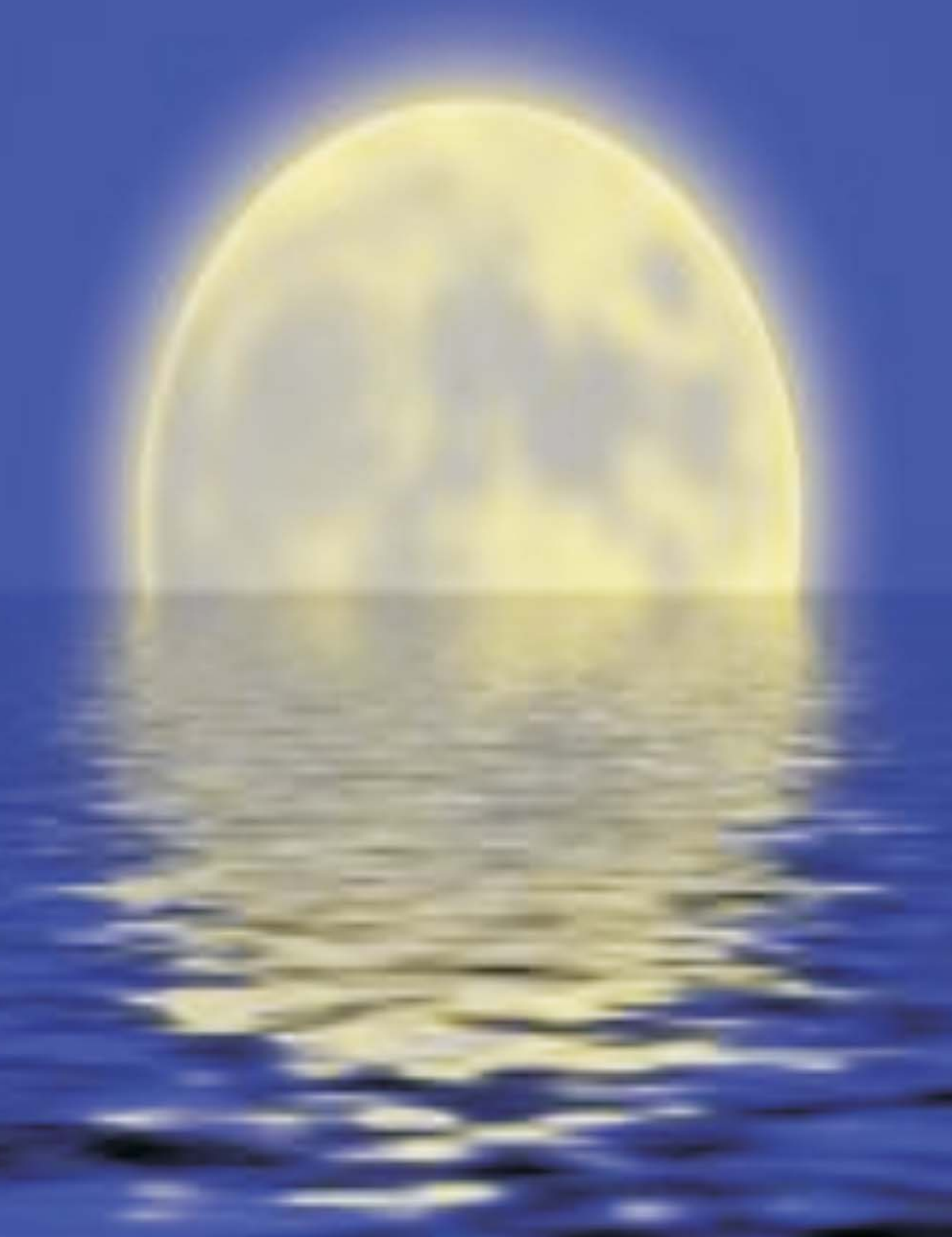